Article

\title{
Application of a Multiplex Polymerase Chain Reaction Test for Diagnosing Bacterial Enteritis in Children in a Real-Life Clinical Setting
}

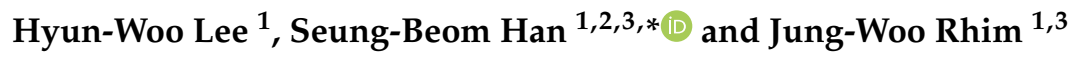 \\ 1 Department of Pediatrics, College of Medicine, The Catholic University of Korea, Seoul 06591, Korea; \\ zzangwoo91@naver.com (H.-W.L.); jwrhim@catholic.ac.kr (J.-W.R.) \\ 2 The Vaccine Bio Research Institute, College of Medicine, The Catholic University of Korea, Seoul 06591, Korea \\ 3 Department of Pediatrics, Daejeon St. Mary's Hospital, The Catholic University of Korea, \\ Daejeon 34943, Korea \\ * Correspondence: beomsid@catholic.ac.kr; Tel.: +82-42-220-9218
}

check for updates

Citation: Lee, H.-W.; Han, S.-B.;

Rhim, J.-W. Application of a

Multiplex Polymerase Chain Reaction Test for Diagnosing Bacterial Enteritis in Children in a Real-Life Clinical Setting. Children 2021, 8, 538. https:// doi.org/10.3390/children 8070538

Academic Editor: Sari A. Acra

Received: 21 May 2021

Accepted: 21 June 2021

Published: 24 June 2021

Publisher's Note: MDPI stays neutral with regard to jurisdictional claims in published maps and institutional affiliations.

Copyright: (c) 2021 by the authors. Licensee MDPI, Basel, Switzerland. This article is an open access article distributed under the terms and conditions of the Creative Commons Attribution (CC BY) license (https:/ / creativecommons.org/licenses/by/ $4.0 /)$.

\begin{abstract}
This study aimed to determine the subjects for bacterial multiplex polymerase chain reaction (mPCR) testing and to interpret the mPCR test results based on patients' clinical symptoms and diagnoses. The medical records of 710 pediatric patients who underwent a bacterial mPCR test were retrospectively reviewed. Clinical characteristics and $\mathrm{MPCR}$ test results were compared between patients with positive $(n=199)$ and negative mPCR test results $(n=511)$ and between patients with invasive pathogens $(n=95)$ and toxigenic pathogens $(n=70)$. Positive mPCR test results were significantly associated with older age $(p<0.001)$, diagnosis of acute gastroenteritis $(p=0.021)$, presence of hematochezia $(p<0.001)$, and absence of cough $(p=0.004)$. The diagnosis of acute gastroenteritis $(p=0.003)$, presence of fever $(p=0.027)$ and diarrhea $(p=0.043)$, and higher C-reactive protein levels ( $p=0.025$ ) were significantly associated with the identification of invasive pathogens in patients with positive $\mathrm{mPCR}$ test results. Thus, selective bacterial mPCR testing should be performed based on the patients' clinical symptoms and diagnoses, and the results should be interpreted in consideration with identified pathogens.
\end{abstract}

Keywords: gastroenteritis; polymerase chain reaction; bacteria; child

\section{Introduction}

Infectious acute gastroenteritis (AGE) is caused by various viruses, bacteria, and parasites [1]. Each of these pathogens causes various gastrointestinal (GI) symptoms and some of them induce similar GI symptoms [1]. Therefore, determining the causative pathogen on the basis of only patient's symptoms is difficult. Moreover, performing various laboratory studies targeting each GI pathogen in each patient is time consuming, laborious, and thus, not cost-effective [2]. To improve the use of multiple test runs, a syndromic diagnosis has been used to identify the pathogens of infectious AGE, and multiplex polymerase chain reaction ( $\mathrm{MPCR}$ ) testing is representative [2]. Although there have been several studies on MPCR tests to identify GI pathogenic bacteria using stool samples [3-11], most of them evaluated the performance of mPCR tests on stool samples as requested by clinicians, without considering the patients' GI symptoms or clinical diagnoses [7-11]. However, vomiting and diarrhea, the major symptoms of infectious AGE, can be caused by infections in systems other than the GI tract, such as the respiratory tract, urinary tract, and central nervous system, as well as by toxins, medications, and noninfectious neurological, endocrine, and allergic diseases [12,13]. Prolonged excretion of GI pathogens colonizing the GI tract after an improvement in symptomatic or asymptomatic infection might be detected by performing an $\mathrm{MPCR}$ test $[2,4]$. In a real-life clinical setting, it is difficult to determine whether unexpected GI pathogens detected after conducting 
an mPCR test are the causative agents of infectious AGE or bystanders found in patients with GI symptoms accompanied by diseases other than infectious AGE. This situation may confound the selection of appropriate treatments and infection control measures. Therefore, a bacterial mPCR test should be performed selectively in patients with GI symptoms consistent with bacterial AGE, and its results should be interpreted based on patients' symptoms and clinical diagnoses.

This retrospective study aimed to determine the subjects for bacterial mPCR testing and to interpret the MPCR test results based on patients' clinical symptoms and diagnoses in pediatric patients. These results can be used as a basis for deciding the appropriate application of a bacterial $\mathrm{mPCR}$ test and interpretation of its results in pediatric patients with GI symptoms.

\section{Materials and Methods}

\subsection{Patients and Study Design}

Pediatric patients (aged < 19 years) who were admitted to the Department of Pediatrics of Daejeon St. Mary's Hospital (Daejeon, Korea) between June 2015 and August 2019 and underwent bacterial $\mathrm{mPCR}$ testing were considered for this study. Patients with GI symptoms that developed $>48 \mathrm{~h}$ after admission or $\leq 48 \mathrm{~h}$ after a previous discharge from the hospital were considered to have hospital-acquired infections and were excluded. Additionally, patients with chronic underlying diseases or chronic diarrhea persisting for $\geq 2$ weeks were excluded. The medical records of the included patients were reviewed retrospectively to collect demographic data including age and sex, clinical data including the patient's symptoms, clinical diagnoses leading to admission, and fever duration, and laboratory data including complete blood cell count, erythrocyte sedimentation rate (ESR), C-reactive protein (CRP) and electrolyte levels, and liver and kidney function test results. The included patients were divided into two groups based on their MPCR test results: positive and negative $\mathrm{MPCR}$ test groups. For the positive MPCR test group, patients were further categorized into invasive pathogen and toxigenic pathogen groups based on the identified bacteria; patients with multiple pathogens were excluded. Pathogenic bacteria identified in a small number of patients $(<1 \%$ of the whole study population) were not categorized into the invasive pathogen or toxigenic pathogen groups and were excluded from statistical analyses. The collected data and the distribution of bacteria detected by an $\mathrm{mPCR}$ test were compared between these patient groups. This study was approved by the Institutional Review Board of Daejeon St. Mary's Hospital with a waiver for acquiring informed consent (approval no.: DC19RESI0084).

\subsection{Microbiological Test}

Fresh stool samples collected from admitted patients were transported to the Department of Laboratory Medicine as soon as possible. A Ribospin vRD kit (GeneAll Biotechnology, Seoul, Korea) was used in accordance with the manufacturer's recommendations for DNA extraction, and a bacterial mPCR test was performed using a commercial mPCR test kit (Seeplex ${ }^{\circledR}$ Diarrhea-B1/B2 ACE detection kit, Seegene, Seoul, Korea) in accordance with the manufacturer's recommendations. This mPCR kit can simultaneously detect 10 types of bacterial pathogens, including Campylobacter spp. (C. jejuni and C. coli), Salmonella spp. (S. enterica and S. bongori), Shigella spp. (S. boydii, S. dysenteriae, S. flexneri, and S. sonnei), Clostridium difficile toxin B, Clostridium perfringens, Vibrio spp. (V. cholerae, V. parahaemolyticus, and V. vulnificus), Yersinia enterocolitica, Aeromonas spp. (A. bivalvium, A. hydrophila, A. salmonicida, and A. sobria), Escherichia coli O157:H7, and verotoxin-producing E. coli (VTEC) [11].

\subsection{Statistical Analysis}

To compare the positive and negative mPCR test groups and the invasive pathogen and toxigenic pathogen groups, chi-square and Mann-Whitney $U$ tests were used for categorical and continuous data, respectively. Multivariate analyses of significant factors 
identified in the univariate analyses were performed using a binary logistic regression test to determine those associated with a positive MPCR test result and the identification of invasive GI pathogens by a bacterial mPCR test. The SPSS 21 program (IBM Corporation, Armonk, NY, USA) was used for statistical analyses. The threshold of statistical significance was defined as a $p$-value of 0.05 .

\section{Results}

During the study period, bacterial mPCR tests were performed in 814 pediatric patients. Among them, 49, 43, and 12 patients were excluded due to probable hospitalacquired infections, chronic underlying diseases, and chronic diarrhea, respectively. The remaining 710 patients included in this study had a median age of 5 years (interquartile range [IQR]: 1-9), and 400 (56.3\%) were men. For 199 (28.0\%) patients, at least one of the pathogenic bacteria was identified by performing a bacterial mPCR test (Table 1).

Table 1. Distribution of pathogenic bacteria identified by bacterial multiplex polymerase chain reaction testing.

\begin{tabular}{cc}
\hline Bacteria & Number of Patients $(\boldsymbol{n}=\mathbf{1 9 9})$ \\
\hline Campylobacter spp. & $56(28.1)$ \\
Clostridium difficile & $44(22.1)$ \\
Salmonella spp. & $39(19.6)$ \\
Clostridium perfringens & $26(13.1)$ \\
Aeromonas spp. & $7(3.5)$ \\
Verotoxin-producing Escherichia coli & $3(1.5)$ \\
Shigella spp. & $1(0.5)$ \\
E. coli O157/H7 & $1(0.5)$ \\
Yersinia spp. & $1(0.5)$ \\
Vibrio spp. & $0(0.0)$ \\
Co-detection & $21(10.6)$ \\
Salmonella spp. and C. perfringens & $5(2.5)$ \\
Salmonella spp. and Aeromonas spp. & $1(0.5)$ \\
Campylobacter spp. and C. perfringens & $1(0.5)$ \\
Campylobacter spp. and Aeromonas spp. & $4(2.0)$ \\
Campylobacter spp. and C. difficile & $2(1.0)$ \\
Campylobacter spp., C. difficile and Aeromonas spp. & $1(0.5)$ \\
C. difficile and C. perfringens & $1(0.5)$ \\
C. difficile and Shigella spp. & $5(2.5)$ \\
\hline
\end{tabular}

Two and three types of bacteria were co-detected in 19 (9.5\%) and two (1.0\%) patients, respectively. Co-detection of bacteria was reported in $12.5 \%$ of Campylobacter infections, $15.4 \%$ of $C$. difficile infections, $15.2 \%$ of Salmonella infections, $36.6 \%$ of $C$. perfringens infections, and $47.1 \%$ of Aeromonas infections. As a single pathogen, Campylobacter spp., C. difficile, Salmonella spp., and C. perfringens were the most frequently identified pathogens (Table 1). Excluding rarely identified pathogens, the most frequently identified four pathogens were categorized into invasive and toxigenic pathogens based on their pathogenic mechanisms [14]. Patients with Campylobacter spp. and Salmonella spp. were categorized in the invasive pathogen group $(n=95)$, and those with $C$. difficile and C. perfringens were categorized in the toxigenic pathogen group $(n=70)$. The remaining bacteria, comprising $6.5 \%$ of the positive mPCR test results, were excluded from further statistical analyses.

\subsection{Comparison between the Positive and Negative mPCR Test Groups}

Among the 710 patients, 511 (72.0\%) and 199 (28.0\%) patients were assigned to the negative and positive $\mathrm{mPCR}$ test groups, respectively (Table 2). Older age, diagnosis of AGE, presence of fever and GI symptoms, absence of respiratory symptoms, and high 
ESR and CRP levels were significantly associated with a positive mPCR test result in the univariate analysis (Table 2).

Table 2. Comparison between patients with positive and negative MPCR test results.

\begin{tabular}{|c|c|c|c|}
\hline Factor & $\begin{array}{l}\text { Negative mPCR Test Group } \\
\qquad(n=511)\end{array}$ & $\begin{array}{l}\text { Positive mPCR Test Group } \\
\qquad(n=199)\end{array}$ & $p$-Value \\
\hline \multicolumn{4}{|l|}{ Demographic factor } \\
\hline Male sex & $284(55.6)$ & $116(58.3)$ & 0.513 \\
\hline Age, years, median (IQR) & $4(1-8)$ & $6(3-11)$ & $<0.001$ \\
\hline Clinical diagnosis & & & $<0.001$ \\
\hline AGE & $304(59.5)$ & $163(81.9)$ & \\
\hline Non-AGE & $207(40.5)$ & $36(18.1)$ & \\
\hline URI & $79(15.5)$ & $13(6.5)$ & \\
\hline LRI & $47(9.2)$ & $6(3.0)$ & \\
\hline Other GI disorders & $28(5.5)$ & $5(2.5)$ & \\
\hline FWLS & $17(3.3)$ & $4(2.0)$ & \\
\hline Urinary tract infection & $12(2.3)$ & $1(0.5)$ & \\
\hline Exanthem subitum & $9(1.8)$ & $3(1.5)$ & \\
\hline CNS disorders & $7(1.4)$ & $3(1.5)$ & \\
\hline Others & $8(1.6)$ & $1(0.5)$ & \\
\hline \multicolumn{4}{|l|}{ Clinical symptoms } \\
\hline Fever & $383(75.0)$ & $173(86.9)$ & 0.001 \\
\hline Vomiting & $310(60.7)$ & $106(53.3)$ & 0.072 \\
\hline Diarrhea & $314(61.4)$ & $156(78.8)$ & $<0.001$ \\
\hline Abdominal pain & $279(54.7)$ & $144(72.4)$ & $<0.001$ \\
\hline Hematochezia & $27(5.3)$ & $35(17.6)$ & $<0.001$ \\
\hline Cough & $143(28.0)$ & $18(9.0)$ & $<0.001$ \\
\hline Rhinorrhea & $147(28.8)$ & $27(13.6)$ & $<0.001$ \\
\hline Sputum & $109(21.3)$ & $16(8.0)$ & $<0.001$ \\
\hline Sore throat & $18(3.5)$ & $6(3.0)$ & 0.737 \\
\hline \multicolumn{4}{|c|}{ Laboratory finding, median (IQR) } \\
\hline WBC count, cells $/ \mu \mathrm{L}$ & $10,450(7500-13,600)$ & $9900(7000-13,100)$ & 0.153 \\
\hline ANC, cells $/ \mu \mathrm{L}$ & $6474(4046-9840)$ & $7050(4320-10,350)$ & 0.365 \\
\hline ALC, cells $/ \mu \mathrm{L}$ & $2085(1290-3289)$ & $1463(1068-2496)$ & $<0.001$ \\
\hline $\mathrm{ESR}, \mathrm{mm} / \mathrm{h}$ & $7(2-17)$ & $13(5-21)$ & $<0.001$ \\
\hline $\mathrm{CRP}, \mathrm{mg} / \mathrm{dL}$ & $1.12(0.17-3.99)$ & $3.63(0.78-7.83)$ & $<0.001$ \\
\hline
\end{tabular}

mPCR: multiplex polymerase chain reaction; IQR: interquartile range; AGE: acute gastroenteritis; URI: upper respiratory infection; LRI: lower respiratory infection; GI: gastrointestinal; FWLS: fever without localizing signs; CNS: central nervous system; WBC: white blood cell; ANC: absolute neutrophil count; ALC: absolute lymphocyte count; ESR: erythrocyte sedimentation rate; CRP: C-reactive protein.

In the multivariate analysis, a positive $\mathrm{MPCR}$ test result was significantly associated with older age $(p<0.001)$, diagnosis of $\operatorname{AGE}(p=0.021)$, presence of hematochezia $(p<0.001)$, and absence of cough $(p=0.004$, Table 3$)$. Among 36 patients diagnosed with non-AGE in the positive mPCR test group, C. difficile, C. perfringens, and C. difficile and C. perfringens were identified in 19, seven, and three patients, respectively. Aeromonas spp. and Salmonella spp. were identified in two patients, and Campylobacter spp., VTEC, and Salmonella spp. and C. perfringens were identified in one patient each.

\subsection{Comparison between the Invasive Pathogen and Toxigenic Pathogen Groups}

The invasive pathogen group consisted of 56 and 39 patients in whom Campylobacter spp. and Salmonella spp. were identified, respectively. The toxigenic pathogen group consisted of 44 and 26 patients in whom C. difficile and C. perfringens were identified, respectively. In the univariate analysis, the detection of invasive pathogens was significantly associated with older age, diagnosis of AGE, presence of fever, diarrhea, and abdominal pain, absence of vomiting and respiratory symptoms, and high ESR and CRP levels (Table 4). 
Table 3. Multivariate analysis for significant factors associated with positive mPCR test results.

\begin{tabular}{cccc}
\hline Factor & Odds Ratio & 95\% Confidence Interval & $p$-Value \\
\hline Age, years & 1.099 & $1.044-1.158$ & $<0.001$ \\
Diagnosis of AGE (vs. non-AGE) & 1.935 & $1.105-3.389$ & 0.021 \\
Fever & 2.877 & $1.628-5.082$ & $<0.001$ \\
Diarrhea & 1.552 & $0.962-2.504$ & 0.072 \\
Abdominal pain & 0.889 & $0.548-1.442$ & 0.633 \\
Hematochezia & 5.011 & $2.675-9.385$ & $<0.001$ \\
Cough & 0.203 & $0.069-0.602$ & 0.004 \\
Rhinorrhea & 1.779 & $0.785-4.027$ & 0.167 \\
Sputum & 1.153 & $0.407-3.270$ & 0.789 \\
ALC, cells/ $\mu \mathrm{L}$ & 1.000 & $1.000-1.000$ & 0.619 \\
ESR, mm/h & 1.001 & $0.991-1.010$ & 0.906 \\
CRP, mg/dL & 1.033 & $0.987-1.082$ & 0.156
\end{tabular}

mPCR: multiplex polymerase chain reaction; AGE: acute gastroenteritis; ALC: absolute lymphocyte count; ESR: erythrocyte sedimentation rate; CRP: C-reactive protein.

Table 4. Comparison between the invasive pathogen and toxigenic pathogen groups.

\begin{tabular}{|c|c|c|c|}
\hline Factor & $\begin{array}{l}\text { Invasive Pathogen Group } \\
\qquad(n=95)\end{array}$ & $\begin{array}{l}\text { Toxigenic Pathogen Group } \\
\qquad(n=70)\end{array}$ & $p$-Value \\
\hline \multicolumn{4}{|l|}{ Demographic factor } \\
\hline Male sex & $56(58.9)$ & $41(58.6)$ & 0.961 \\
\hline Age, years, median (IQR) & $8(4-12)$ & $5(1-11)$ & 0.009 \\
\hline Age group & & & 0.009 \\
\hline$<2$ years & $8(8.4)$ & $18(25.7)$ & \\
\hline $2-8$ years & $43(45.3)$ & $28(40.0)$ & \\
\hline$>8$ years & $44(46.3)$ & $24(34.3)$ & \\
\hline Clinical diagnosis & & & $<0.001$ \\
\hline AGE & $92(96.8)$ & $44(62.9)$ & \\
\hline Non-AGE & $3(3.2)$ & $26(37.1)$ & \\
\hline URI & $1(1.1)$ & $10(14.3)$ & \\
\hline LRI & $0(0.0)$ & $5(7.1)$ & \\
\hline Other GI disorders & $1(1.1)$ & $3(4.3)$ & \\
\hline FWLS & $1(1.1)$ & $1(1.4)$ & \\
\hline Urinary tract infection & $0(0.0)$ & $1(1.4)$ & \\
\hline Exanthem subitum & $0(0.0)$ & $2(2.9)$ & \\
\hline CNS disorders & $0(0.0)$ & $3(4.3)$ & \\
\hline Others & $0(0.0)$ & $1(1.4)$ & \\
\hline \multicolumn{4}{|l|}{ Clinical symptoms } \\
\hline Fever & $94(98.9)$ & $51(72.9)$ & $<0.001$ \\
\hline Vomiting & $44(46.3)$ & $45(64.3)$ & 0.022 \\
\hline Diarrhea & $91(95.8)$ & $39(56.5)$ & $<0.001$ \\
\hline Abdominal pain & $83(87.4)$ & $39(55.7)$ & $<0.001$ \\
\hline Hematochezia & $22(23.2)$ & $8(11.4)$ & 0.054 \\
\hline Cough & $4(4.2)$ & $12(17.1)$ & 0.006 \\
\hline Rhinorrhea & $7(7.4)$ & $15(21.7)$ & 0.008 \\
\hline Sputum & $3(3.2)$ & $10(14.3)$ & 0.009 \\
\hline Sore throat & $4(4.2)$ & $0(0.0)$ & 0.138 \\
\hline \multicolumn{4}{|c|}{ Laboratory finding, median (IQR) } \\
\hline WBC count, cells $/ \mu \mathrm{L}$ & $9900(6900-12,850)$ & $9600(6700-12,950)$ & 0.765 \\
\hline ANC, cells $/ \mu \mathrm{L}$ & 7050 (4906-10,042) & $5588(3234-10,946)$ & 0.215 \\
\hline ALC, cells $/ \mu \mathrm{L}$ & $1380(1045-1730)$ & $1970(938-3661)$ & 0.019 \\
\hline $\mathrm{ESR}, \mathrm{mm} / \mathrm{h}$ & $17(11-23)$ & $5(2-13)$ & $<0.001$ \\
\hline $\mathrm{CRP}, \mathrm{mg} / \mathrm{dL}$ & $6.53(3.04-9.89)$ & $0.56(0.21-2.47)$ & $<0.001$ \\
\hline
\end{tabular}

IQR: interquartile range; AGE: acute gastroenteritis; URI: upper respiratory infection; LRI: lower respiratory infection; GI: gastrointestinal; FWLS: fever without localizing signs; CNS: central nervous system; WBC: white blood cell; ANC: absolute neutrophil count; ALC: absolute lymphocyte count; ESR: erythrocyte sedimentation rate; CRP: C-reactive protein. 
In the multivariate analysis, diagnosis of AGE $(p=0.003)$, presence of fever $(p=0.027)$ and diarrhea $(p=0.043)$, and high CRP levels $(p=0.025)$ were significantly associated with the detection of invasive pathogens (Table 5). For the 44 patients with positive results for $C$. difficile, the median age was 3 years (IQR: $1-8)$, and 14 (31.8\%) were aged <2 years. Histories of hospitalization and antibiotic therapy within the previous 2 months were identified in eight (18.2\%) and 19 (43.2\%) patients, respectively. Metronidazole treatment was administered to $13(29.5 \%)$ patients. AGE was more frequently diagnosed in patients who received metronidazole treatment $(11 / 13,84.6 \%)$ than in those who did not receive metronidazole treatment $(14 / 31,45.2 \% ; p=0.016)$.

Table 5. Multivariate analysis for significant factors associated with the identification of invasive pathogens.

\begin{tabular}{cccc}
\hline Factor & Odds Ratio & 95\% Confidence Interval & $p$-Value \\
\hline Age, years & 1.013 & $0.892-1.150$ & 0.847 \\
Diagnosis of AGE (vs. non-AGE) & 37.846 & $3.498-409.472$ & 0.003 \\
Fever & 13.394 & $1.350-132.889$ & 0.027 \\
Vomiting & 0.417 & $0.145-1.197$ & 0.104 \\
Diarrhea & 5.007 & $1.050-23.874$ & 0.043 \\
Abdominal pain & 2.014 & $0.492-8.252$ & 0.330 \\
Cough & 0.145 & $0.003-6.807$ & 0.326 \\
Rhinorrhea & 1.807 & $0.113-28.976$ & 0.676 \\
Sputum & 9.399 & $0.382-231.491$ & 0.170 \\
ALC, cells/ $\mu \mathrm{L}$ & 1.000 & $1.000-1.000$ & 0.855 \\
ESR, mm/h & 1.059 & $0.997-1.125$ & 0.064 \\
CRP, mg/dL & 1.187 & $1.021-1.379$ & 0.025 \\
\hline
\end{tabular}

AGE: acute gastroenteritis; ALC: absolute lymphocyte count; ESR: erythrocyte sedimentation rate; CRP: C-reactive protein.

\section{Discussion}

In this study, the results of bacterial $\mathrm{mPCR}$ tests performed in pediatric patients in a real-life clinical setting were analyzed. Clinical diagnosis of AGE and the presence of fever were significantly associated with a positive result in a bacterial mPCR test and identification of invasive GI pathogens.

Various mPCR tests for GI pathogenic bacteria have been reported to have favorable diagnostic performance [4-11]; however, a few studies have evaluated the performance of these tests based on the patients' clinical diagnoses $[6,15,16]$. Viruses rather than bacteria are major causes of infectious AGE, and a specific antibiotic therapy is not urgently required in most cases of community-acquired bacterial AGE in immunocompetent patients [1] Therefore, a bacterial mPCR test should be performed selectively in patients with suspected bacterial AGE, which would, in turn, increase the diagnostic accuracy of the bacterial mPCR test, reduce associated costs and labor, and avoid unnecessary patient discomfort. Older age was significantly associated with a positive bacterial mPCR test result in the multivariate analysis in this study. However, the exact age with acceptable sensitivity and specificity for the identification of pathogenic bacteria could not be defined. Although the presence of hematochezia and the absence of cough were significantly associated with a positive mPCR test result, only $17.6 \%$ and $28.0 \%$ of patients in the positive and negative mPCR test groups, respectively, exhibited these symptoms. Therefore, their usefulness in determining subjects for bacterial mPCR testing should be small.

In this study, one-third of the included patients underwent bacterial mPCR testing but were not clinically diagnosed with AGE. Since the diagnosis of AGE was significantly associated with a positive $\mathrm{MPCR}$ test result and identification of invasive pathogens that are potential candidates for antibiotic therapy, selective bacterial $\mathrm{mPCR}$ testing in patients who are clinically diagnosed with infectious AGE should be encouraged. Recent advancements in microbiological laboratory methods tend to enhance physicians' dependence on laboratory test results more than patient history and physical examination. However, 
microbiological tests should be performed according to the presumptive diagnosis made based on the patient's history and physician's examination [17]. The results of this study emphasized the importance of thorough history taking and physical examination for making an accurate clinical diagnosis. Some patients may complain of vomiting only when coughing, abdominal pain developed after severe coughing, or loose stool not consistent with diarrhea ( $<3$ episodes in a day). If the primary clinical diagnosis is infections other than AGE, such as respiratory tract and urinary tract infections, bacterial mPCR testing can be omitted. Because respiratory tract infection was the most frequent diagnosis in non-AGE cases, detailed history taking and physical examination to determine whether AGE and respiratory tract infection co-exist or whether respiratory symptoms promote GI symptoms are required. To reduce unnecessary stool examination in patients presenting with concurrent GI and respiratory symptoms, the order of development, trend of severity, and simultaneity of the GI and respiratory symptoms should be considered during clinical diagnosis. Among 243 patients diagnosed with non-AGE, 36 (14.8\%) patients showed positive $\mathrm{mPCR}$ test results. However, C. difficile and C. perfringens were identified in $80.6 \%$ of them, and Campylobacter spp. and Salmonella spp., in which antibiotic therapy were potentially required, were identified only in four ( $0.6 \%$ of the whole study population) patients. Selective bacterial $\mathrm{mPCR}$ testing in patients clinically diagnosed with AGE could exempted $34.2 \%$ of the included patients from expensive testing and increased the positive rate of the $\mathrm{mPCR}$ test from $28.0 \%$ to $34.9 \%$.

Among patients in whom C. difficile was identified, $29.5 \%$ received metronidazole treatment. Although some patients with $C$. difficile infection recover without specific antibiotic treatment [18], AGE was diagnosed significantly less in patients who did not receive metronidazole treatment than in those who did. The colonization rate of $C$. difficile is higher in infants and young children than in adolescents and adults, and by 3 years of age, it decreases and becomes similar to that of adults [18]. C. difficile testing should not be routinely recommended for infants with diarrhea and for children aged 1-2 years without the exclusion of other causes of diarrhea [19]. Even for children aged $\geq 2$ years, $C$. difficile testing is recommended for children with risk factors or exposure history to $C$. difficile infection [19]. In the positive mPCR test group of this study, the positive rate of $C$. difficile was significantly higher in children aged $<2$ years than in those aged $\geq 2$ years $(51.5 \%$ vs. $21.1 \%, p<0.001)$. Moreover, approximately one-third of patients in whom $C$. difficile was detected were aged $<2$ years, and less than half of them had risk factors for $C$. difficile infection. Therefore, the diagnosis of $C$. difficile infection should not be solely dependent on mPCR testing, but should be confirmed using a multistep algorithm that considers patients' age, symptoms, and risk factors [18]. In a previous study using the same multiplex PCR test kit used in this study, C. perfringens was most frequently detected in children with diarrhea; however, confirmatory tests revealed that the PCR tests showed false positive results [11]. A recent meta-analysis reported low sensitivity (31\%) and positive predictive value (49\%) of nucleic acid amplification tests against culture for diagnosing C. perfringens-associated diseases [20]. Considering that Clostridium spp. are more likely to exist as intestinal flora than Campylobacter spp. and Salmonella spp. [19,21-23], determining whether the bacteria detected by an mPCR test are true pathogens is more difficult in cases of Clostridium spp. than in cases of invasive pathogens. Furthermore, other bacteria were co-detected in $36.6 \%$ of the C. perfringens-positive patients in this study. Therefore, universal inclusion of Clostridium spp. in bacterial mPCR testing seems to be unnecessary for immunocompetent pediatric patients with GI symptoms. Besides, a high number of $C$. perfringens organisms are needed to cause GI symptoms; therefore, the usefulness of quantitative PCR tests for C. perfringens should be investigated [20].

As the presence of fever and diarrhea and higher CRP levels were significantly associated with the identification of invasive pathogens, patients complaining of fever with definite diarrhea rather than prominent vomiting and elevated CRP levels could be subjects for bacterial mPCR testing among those clinically diagnosed with AGE. In developed countries including Korea, Salmonella spp. and Campylobacter spp. are the most common 
pathogens causing bacterial AGE $[15,16,24-26]$, and they were also most frequently detected in this study. Since Shigella spp. and Vibrio spp. are rarely identified in patients with AGE in developed countries and that no specific treatment is recommended for AGE caused by Aeromonas spp. and Yersinia spp. [24,25], a selective test in patients with community-acquired AGE would be more appropriate than a universal test for detecting these bacteria. Enteropathogenic and enteroaggregative E. coli were considered major pathogens of bacterial AGE in children, although they were not tested in this study [27]. Therefore, an mPCR test targeting only the most common GI pathogens, including Campylobacter spp., Salmonella spp., diarrheagenic E. coli, rotavirus, and norovirus, should be suitable for patients with community-acquired AGE. Additional tests for rare pathogens can be considered in patients with negative primary test results, risk factors for severe AGE, or immunodeficiency.

This study had some limitations. First, this was a retrospective study that included only hospitalized patients. Thus, some patients with mild symptoms of bacterial AGE might have been managed in the outpatient clinic or have not been subjected for MPCR testing during hospitalization, and hence, excluded from this study. However, the observation that one-third of patients who underwent the MPCR test were not diagnosed with AGE and two-thirds of patients with AGE were negative for bacterial pathogens suggests that bacterial $\mathrm{mPCR}$ tests were frequently performed in patients presenting GI symptoms in our hospital with a low threshold for performing the test. Second, confirmatory tests for the pathogens most commonly detected by the mPCR test, such as Campylobacter spp. and Clostridium spp., were not performed. However, as mentioned above, the results of this study suggest the limited reliability of MPCR testing in diagnosing Clostridium infection and need for alternative diagnostic tests. Instead, further studies to compare the results of mPCR tests with those of culture tests for Campylobacter spp. and Salmonella spp. should be performed based on patients' clinical diagnoses. Finally, the GI pathogenic viruses were not considered in this study. However, patients with viral AGE might have a marginal impact on the results of this study, unless a significant proportion of them were included in the invasive pathogen group and received unnecessary antibiotic treatment. An mPCR test for GI pathogenic viruses (rotavirus, norovirus, adenovirus, and astrovirus) was simultaneously performed in $432(60.8 \%)$ patients using a commercial kit (Seeplex ${ }^{\circledR}$ Diarrhea-V ACE Detection kit, Seegene): Viral pathogens were identified in 112 (25.9\%) patients, and only two $(1.8 \%)$ of them were identified in the invasive pathogen group.

\section{Conclusions}

In conclusion, a bacterial mPCR test should be performed selectively, and its results should be cautiously interpreted considering patients' clinical symptoms and diagnoses and identified pathogens. Since some of the GI pathogens are rarely detected even in patients with AGE and $C$. difficile seems to be a bystander rather than a causative pathogen in most cases, an mPCR test for a limited number of common GI pathogens should be performed in real-life clinical settings.

Author Contributions: Conceptualization, S.-B.H. and J.-W.R.; methodology, S.-B.H.; formal analysis, S.-B.H. and H.-W.L.; investigation, H.-W.L. and S.-B.H.; data curation, S.-B.H. and J.-W.R.; writingoriginal draft preparation, H.-W.L. and S.-B.H.; writing-review and editing, J.-W.R. All authors have read and agreed to the published version of the manuscript.

Funding: This research received no external funding.

Institutional Review Board Statement: The study was conducted in accordance with the guidelines of the Declaration of Helsinki, and approved by the Institutional Review Board of Daejeon St. Mary's Hospital with a waiver for acquiring informed consent (approval no.: DC19RESI0084).

Informed Consent Statement: Patient consent was waived due to the retrospective nature of this study. 
Data Availability Statement: The data presented in this study are available on request from the corresponding author. The data are not publicly available due to national regulations.

Acknowledgments: We thank Joonhong Park for his contribution to microbiological tests.

Conflicts of Interest: The authors declare no conflict of interest.

\section{References}

1. Yi, J.; Shane, A. Approach to the diagnosis and management of gastrointestinal tract infections. In Principles and Practice of Pediatric Infectious Diseases, 5th ed.; Long, S.S., Prober, C.G., Fischer, M., Eds.; Elsevier: Philadelphia, PA, USA, 2018 ; pp. 376-383.

2. Anderson, N.W.; Tarr, P.I. Multiplex nucleic acid amplification testing to diagnose gut infections: Challenges, opportunities, and result interpretation. Gastroenterol. Clin. N. Am. 2018, 47, 793-812. [CrossRef]

3. Wohlwend, N.; Tiermann, S.; Risch, L.; Risch, M.; Bodmer, T. Evaluation of a multiplex real-time PCR assay for detecting major bacterial enteric pathogens in fecal specimens: Intestinal inflammation and bacterial load are correlated in Campylobacter infections. J. Clin. Microbiol. 2016, 54, 2262-2266. [CrossRef]

4. Kellner, T.; Parsons, B.; Chui, L.; Berenger, B.M.; Xie, J.; Burnham, C.A.; Tarr, P.I.; Lee, B.E.; Nettel-Aguirre, A.; Szelewicki, J.; et al. Comparative evaluation of enteric bacterial culture and a molecular multiplex syndromic panel in children with acute gastroenteritis. J. Clin. Microbiol. 2019, 57, e00205-19. [CrossRef]

5. Cybulski, R.J., Jr.; Bateman, A.C.; Bourassa, L.; Bryan, A.; Beail, B.; Matsumoto, J.; Cookson, B.T.; Fang, F.C. Clinical impact of a multiplex gastrointestinal polymerase chain reaction panel in patients with acute gastroenteritis. Clin. Infect. Dis. 2018, 67, 1688-1696. [CrossRef]

6. O'Leary, J.; Corcoran, D.; Lucey, B. Comparison of the EntericBio multiplex PCR system with routine culture for detection of bacterial enteric pathogens. J. Clin. Microbiol. 2009, 47, 3449-3453. [CrossRef]

7. De Boer, R.F.; Ott, A.; Kesztyus, B.; Kooistra-Smid, A.M. Improved detection of five major gastrointestinal pathogens by use of a molecular screening approach. J. Clin. Microbiol. 2010, 48, 4140-4146. [CrossRef]

8. Buss, S.N.; Leber, A.; Chapin, K.; Fey, P.D.; Bankowski, M.J.; Jones, M.K.; Rogatcheva, M.; Kanack, K.J.; Bourzac, K.M. Multicenter evaluation of the BioFire FilmArray gastrointestinal panel for etiologic diagnosis of infectious gastroenteritis. J. Clin. Microbiol. 2015, 53, 915-925. [CrossRef] [PubMed]

9. Harrington, S.M.; Buchan, B.W.; Doern, C.; Fader, R.; Ferraro, M.J.; Pillai, D.R.; Rychert, J.; Doyle, L.; Lainesse, A.; Karchmer, T.; et al. Multicenter evaluation of the BD max enteric bacterial panel PCR assay for rapid detection of Salmonella spp., Shigella spp., Campylobacter spp. (C. jejuni and C. coli), and Shiga toxin 1 and 2 genes. J. Clin. Microbiol. 2015, 53, 1639-1647. [CrossRef] [PubMed]

10. Claas, E.C.; Burnham, C.A.; Mazzulli, T.; Templeton, K.; Topin, F. Performance of the xTAG(R) gastrointestinal pathogen panel, a multiplex molecular assay for simultaneous detection of bacterial, viral, and parasitic causes of infectious gastroenteritis. $J$. Microbiol. Biotechnol. 2013, 23, 1041-1045. [CrossRef]

11. Onori, M.; Coltella, L.; Mancinelli, L.; Argentieri, M.; Menichella, D.; Villani, A.; Grandin, A.; Valentini, D.; Raponi, M.; Russo, C. Evaluation of a multiplex PCR assay for simultaneous detection of bacterial and viral enteropathogens in stool samples of paediatric patients. Diagn. Microbiol. Infect. Dis. 2014, 79, 149-154. [CrossRef] [PubMed]

12. Gupta, R. Diarrhea. In Pediatric Gastrointestinal and Liver Disease, 5th ed.; Wyllie, R., Hyams, J.S., Kay, M., Eds.; Elsevier: Philadelphia, PA, USA, 2016; pp. 104-114.

13. Li, B.; Kovaci, K. Vomiting. In Pediatric Gastrointestinal and Liver Disease, 5th ed.; Wyllie, R., Hyams, J.S., Kay, M., Eds.; Elsevier: Philadelphia, PA, USA, 2016; pp. 84-103.

14. Kotloff, K.L. Acute gastroenteritis in children. In Nelson Textbook of Pediatrics, 21th ed.; Kliegman, R.M., St Geme, J.W., Blum, N.J., Shah, S.S., Tasker, R.C., Wilson, K.M., Eds.; Elsevier: Philadelphia, PA, USA, 2020; pp. 2012-2033.

15. Friesema, I.H.; de Boer, R.F.; Duizer, E.; Kortbeek, L.M.; Notermans, D.W.; Norbruis, O.F.; Bezemer, D.D.L.; van Heerbeek, H.; van Andel, R.N.J.; van Enk, J.G.; et al. Etiology of acute gastroenteritis in children requiring hospitalization in the Netherlands. Eur. J. Clin. Microbiol. Infect. Dis. 2012, 31, 405-415. [CrossRef]

16. Xie, J.; Nettel-Aguirre, A.; Lee, B.E.; Chui, L.; Pang, X.L.; Zhuo, R.; Parsons, B.; Vanderkooi, O.G.; Tarr, P.I.; Ali, S.; et al. Relationship between enteric pathogens and acute gastroenteritis disease severity: A prospective cohort study. Clin. Microbiol. Infect. 2019, 25, 454-461. [CrossRef]

17. Fisher, R.G.; Boyce, T.G.; Correa, A.G. Moffet's Pediatric Infectious Diseases: A Problem-Oriented Approach, 5th ed.; Lippincott Williams \& Wilkins: Philadelphia, PA, USA, 2017; pp. 1-12.

18. Schutze, G.E.; Willoughby, R.E.; Committee on Infectious Diseases; American Academy of Pediatrics. Clostridium difficile infection in infants and children. Pediatrics 2013, 131, 196-200. [PubMed]

19. McDonald, L.C.; Gerding, D.N.; Johnson, S.; Bakken, J.S.; Carroll, K.C.; Coffin, S.E.; Dubberke, E.R.; Garey, K.W.; Gould, C.V.; Kelly, C.; et al. Clinical Practice Guidelines for Clostridium difficile infection in adults and children: 2017 update by the Infectious Diseases Society of America (IDSA) and Society for Healthcare Epidemiology of America (SHEA). Clin. Infect. Dis. 2018, 66, e1-e48. [CrossRef] [PubMed] 
20. Chen, K.; Ahmed, S.; Sheng, Y.J.; Sun, C.; Deng, C.L.; Ojhac, S.C. Diagnostic accuracy of nucleic acid amplification-based assays for Clostridium perfringens-associated diseases: A systematic review and meta-analysis. J. Clin. Microbiol. 2020, 58, e00363-20. [CrossRef] [PubMed]

21. Muller, M.; Overturf, G.D. Clostridial intoxication and infection. In Feigin and Cherry's Textbook of Pediatric Infectious Diseases, 8th ed.; Cherry, J.D., Harrison, G.J., Kaplan, S.L., Steinbach, W.J., Hotez, P.J., Eds.; Elsevier: Philadelphia, PA, USA, 2019; pp. 1291-1298.

22. Janssen, R.; Krogfelt, K.A.; Cawthraw, S.A.; van Pelt, W.; Wagenaar, J.A.; Owen, R.J. Host-pathogen interactions in Campylobacter infections: The host perspective. Clin. Microbiol. Rev. 2008, 21, 505-518. [CrossRef]

23. Gal-Mor, O. Persistent infection and long-term carriage of typhoidal and nontyphoidal salmonellae. Clin. Microbiol. Rev. 2019, 32, e00088-18. [CrossRef] [PubMed]

24. Kim, N.; Hong, S.; Chun, J.; Hwang, K.J. Laboratory-based surveillance of water- and food-borne infectious disease-causing bacteria in the Republic of Korea, 2016-2018. Public Health Wkly. Rep. 2019, 12, 898-903.

25. Spina, A.; Kerr, K.G.; Cormican, M.; Barbut, F.; Eigentler, A.; Zerva, L.; Tassios, P.; Popescu, G.A.; Rafila, A.; Eerola, E.; et al. Spectrum of enteropathogens detected by the FilmArray GI Panel in a multicentre study of community-acquired gastroenteritis. Clin. Microbiol. Infect. 2015, 21, 719-728. [CrossRef] [PubMed]

26. Shane, A.L.; Mody, R.K.; Crump, J.A.; Tarr, P.I.; Steiner, T.S.; Kotloff, K.; Langley, J.M.; Wanke, C.; Warren, C.A.; Cheng, A.C.; et al. 2017 Infectious Diseases Society of America Clinical Practice Guidelines for the diagnosis and management of infectious diarrhea. Clin. Infect. Dis. 2017, 65, e45-e80. [CrossRef]

27. Kim, Y.; Kim, H.J.; Lim, S.; Bae, K.S.; Han, S.B.; Jeong, D.C.; Kang, J.H.; Shin, G.J.; Lee, G.D.; Park, Y.J. Community-acquired Escherichia coli enteritis in Korean children: The clinical application of a stool polymerase chain reaction assay. Infect. Chemother. 2017, 49, 275-281. [CrossRef] [PubMed] 